\title{
Silver nanoparticles induce tight junction disruption and astrocyte neurotoxicity in a rat blood-brain barrier primary triple coculture model
}

This article was published in the following Dove Press journal:

International Journal of Nanomedicine

29 September 2015

Number of times this article has been viewed

\author{
Liming $X u^{1,2, *}$ \\ Mo Dan ${ }^{1, *}$ \\ Anliang Shao' \\ Xiang Cheng ${ }^{1,3}$ \\ Cuiping Zhang ${ }^{4}$ \\ Robert A Yokel ${ }^{5}$ \\ Taro Takemura ${ }^{6}$ \\ Nobutaka Hanagata ${ }^{6}$ \\ Masami Niwa ${ }^{7,8}$ \\ Daisuke Watanabe ${ }^{7,8}$ \\ 'National Institutes for Food and \\ Drug Control, No 2, Temple of \\ Heaven, Beijing, ${ }^{2}$ School of Information \\ and Engineering, Wenzhou Medical \\ University, Wenzhou, ${ }^{3}$ School of \\ Materials Science and Engineering, \\ Southwest Jiaotong University, \\ Chengdu, ${ }^{4}$ Beijing Neurosurgical \\ Institute, Capital Medical University, \\ Beijing, People's Republic of China; \\ ${ }^{5}$ College of Pharmacy, University \\ of Kentucky, Lexington, KY, USA; \\ ${ }^{6}$ Nanotechnology Innovation Station \\ for Nanoscale Science and Technology, \\ National Institute for Materials \\ Science, Tsukuba, Ibaraki, ${ }^{7}$ Department \\ of Pharmacology, Nagasaki University, \\ ${ }^{8}$ BBB Laboratory, PharmaCo-Cell \\ Company, Ltd., Nagasaki, Japan \\ *These authors contributed equally \\ to this work
}

Correspondence: Liming Xu; Mo Dan National Institutes for Food and Drug Control, No 2, Temple of Heaven, Beijing 100050, People's Republic of China $\mathrm{Tel} / \mathrm{fax}+86106709566 \mathrm{I}$;

+8610 67872233 ext 8220

Email xuliming@nifdc.org.cn;

danmo@nifdc.org.cn
Background: Silver nanoparticles (Ag-NPs) can enter the brain and induce neurotoxicity. However, the toxicity of Ag-NPs on the blood-brain barrier (BBB) and the underlying mechanism(s) of action on the BBB and the brain are not well understood.

Method: To investigate Ag-NP suspension (Ag-NPS)-induced toxicity, a triple coculture BBB model of rat brain microvascular endothelial cells, pericytes, and astrocytes was established. The BBB permeability and tight junction protein expression in response to Ag-NPS, NP-released Ag ions, and polystyrene-NP exposure were investigated. Ultrastructural changes of the microvascular endothelial cells, pericytes, and astrocytes were observed using transmission electron microscopy (TEM). Global gene expression of astrocytes was measured using a DNA microarray.

Results: A triple coculture BBB model of primary rat brain microvascular endothelial cells, pericytes, and astrocytes was established, with the transendothelial electrical resistance values $>200 \Omega \cdot \mathrm{cm}^{2}$. After Ag-NPS exposure for 24 hours, the BBB permeability was significantly increased and expression of the tight junction (TJ) protein ZO-1 was decreased. Discontinuous TJs were also observed between microvascular endothelial cells. After Ag-NPS exposure, severe mitochondrial shrinkage, vacuolations, endoplasmic reticulum expansion, and Ag-NPs were observed in astrocytes by TEM. Global gene expression analysis showed that three genes were upregulated and 20 genes were downregulated in astrocytes treated with AgNPS. Gene ontology (GO) and Kyoto Encyclopedia of Genes and Genomes (KEGG) pathway analysis showed that the 23 genes were associated with metabolic processes, biosynthetic processes, response to stimuli, cell death, the MAPK pathway, and so on. No GO term and KEGG pathways were changed in the released-ion or polystyrene-NP groups. Ag-NPS inhibited the antioxidant defense of the astrocytes by increasing thioredoxin interacting protein, which inhibits the Trx system, and decreasing Nr4al and Duspl. Meanwhile, Ag-NPS induced inflammation and apoptosis through modulation of the MAPK pathway or B-cell lymphoma-2 expression or mTOR activity in astrocytes.

Conclusion: These results draw our attention to the importance of Ag-NP-induced toxicity on the neurovascular unit and provide a better understanding of its toxicological mechanisms on astrocytes.

Keywords: Ag nanoparticles, astrocytes, BBB model, global gene expression analysis, antioxidant defense

\section{Introduction}

Silver nanoparticles (Ag-NPs) are 1 to 100 nm-sized metallic colloidal particles widely used in engineering, manufacturing, and biomedicine. Compared to bulk silver metal, Ag-NPs showed greater efficacy against bacteria due to their relatively large 
surface area and high fraction of surface atoms. ${ }^{1}$ Currently, Ag-NPs are the most commonly used nanomaterials, being used as antibiotic agents in textiles, medical devices (wound dressings), ${ }^{2}$ and appliances such as refrigerators and washing machines. ${ }^{3}$ However, understanding of Ag-NPs toxicity lags behind the applications for this technology. Inadequate identification of the potential hazards and the management of risks from exposures could lead to serious human health problems. $^{4}$

Brain capillary endothelial cells cooperate with pericytes and astrocytes to generate the unique barrier properties of the blood-brain barrier (BBB), which is part of the neurovascular unit that plays a crucial role in safeguarding the brain from potentially harmful endogenous and exogenous substances circulating in the blood. The BBB, with its tight junctions (TJs) and efflux transporters, restricts the entry of most therapeutic agents. ${ }^{5}$ A promising approach to overcome limited flux into the central nervous system (CNS) is the use of nanoparticles. ${ }^{6}$ However, the risk from nanoparticles for the BBB and CNS still needs more investigations. In recent years, how Ag-NPs induce BBB dysfunction and neurotoxicity has been of particular interest, because Ag-NPs have been shown to enter the brain by crossing the BBB in vitro and in vivo. ${ }^{7-10}$ Previous studies reported that intravenous or subcutaneous injection of Ag-NPs can induce BBB dysfunction, astrocyte swelling, and neuronal degeneration in rats. ${ }^{7-9}$ The BBB permeability mechanisms of Ag-NPs were further investigated using an in vitro $\mathrm{BBB}$ model (cocultures of rat brain microvascular endothelial cells with astrocytes). The results showed that Ag-NPs crossed the BBB mainly by transcytosis rather than through the paracellular pathway. ${ }^{10}$ Another study showed that Ag-NPs can increase BBB permeability and interact with the cerebral microvascular unit, producing a proinflammatory cascade that may further induce brain inflammation and neurotoxicity. ${ }^{11}$ Most of the studies of Ag-NP-induced BBB dysfunction only focused on permeability changes and/or toxicity to the endothelial cells. However, brain microvascular endothelial cells cooperate with pericytes and astrocytes to generate the unique barrier properties of the BBB. The $\mathrm{BBB}$ is part of the neurovascular unit that plays a crucial role in safeguarding the brain from potentially harmful endogenous and exogenous compounds circulating in the blood. ${ }^{5}$ A comprehensive understanding of how Ag-NPs induce BBB dysfunction and cause further toxicity and the mechanisms of action in brain endothelial cells, pericytes, and astrocytes remain largely unknown.

Ag-NPs encounter astrocytes immediately after crossing the BBB, because these brain cells almost completely cover the brain capillaries with their end feet. ${ }^{12}$ Astrocytes are the most abundant cell type in the brain. They provide metabolic nutrients to neurons and protect the brain against oxidative stress and metal toxicity. ${ }^{13,14}$ It is critical to understand how Ag-NPs affect astrocyte functions and induce potential toxicity. Recent studies showed that Ag-NPs accumulated in cultured astrocytes. ${ }^{15-17}$ The accumulated Ag-NPs did not compromise the viability and the basal metabolism of cultured primary astrocytes. Ag-NPs induced upregulation of metallothioneins and heme oxygenase 1 to prevent silvermediated toxicity, which could be induced by Ag-NP-derived Ag ions. ${ }^{16}$ However, another study, using a mixed primary cell model consisting mainly of neurons and astrocytes and a minor proportion of oligodendrocytes, demonstrated that Ag-NPs induced oxidative stress and acute calcium responses. The Ag-NPs were mainly taken up by astrocytes, which changed astrocyte morphology, but not by neurons. ${ }^{17}$ These contradicting results demonstrated that the effects of Ag-NPs on astrocytes remain uncertain. More studies are needed to comprehensively investigate the effects and toxicological mechanism(s) of Ag-NPs on astrocytes after they cross the BBB.

In this study, a triple coculture BBB model comprising microvascular endothelial cells, pericytes, and astrocytes was used to mimic the in vivo anatomical situation. The effects of Ag-NP suspension (Ag-NPS, containing silver nanoparticles and released silver ions) on BBB permeability and toxicity were studied. Polystyrene-NPs (PS-NPs) and Ag-NP-released Ag ions were studied to compare the toxic effects with respect to different raw chemical composition and/or form of silver. BBB permeability was studied after exposure to Ag-NPS and PS-NP. Ultrastructural changes of microvascular endothelial cells, pericytes, and astrocytes were observed by transmission electron microscopy (TEM). Then, DNA microarray was used to detect gene expression profiling of primary rat astrocytes in the triple coculture BBB model after exposure to Ag-NPS, the released Ag ions, and PS-NP. The mechanisms of Ag-NPS-induced toxicity on astrocytes were then evaluated using bioinformatics analyses, combined with observation of cellular morphological changes. Expressions of specific candidate genes were determined using real-time polymerase chain reaction (PCR). The results of this study provide comprehensive insight about Ag-NPS-induced toxicity on the biomimic BBB and the mechanism(s) of Ag-NPS-induced neurotoxicity on astrocytes, which will help us to have a better understanding of the importance of Ag-NPS-induced toxicity on astrocytes in the CNS. 


\section{Materials and methods Characterization of materials}

A Ag-NPS $(2,000 \mu \mathrm{g} / \mathrm{mL})$ was purchased from Nanux (SL1105001, Korea). PS-NP powder was purchased from Base Line Chrom Tech Research Centre (6-1-0005, People's Republic of China). The PS-NP powder was dispersed in sterile deionized water $(2,000 \mu \mathrm{g} / \mathrm{mL})$. The Ag-NP or PS-NP suspensions were then diluted with cell culture medium to the required final concentrations. The suspensions were sonicated $(300 \mathrm{~W}, 42 \mathrm{kHz})$ in an icewater bath for 5 minutes before use. The $\mathrm{Ag}$ ion solution used in this study was prepared by incubating the Ag-NPS $(10 \mu \mathrm{g} / \mathrm{mL})$ for 24 hours at $37^{\circ} \mathrm{C}$ and then centrifuging it at 20,000 rpm for 2 hours. The total $\mathrm{Ag}$ contents before centrifugation and $\mathrm{Ag}$ ions contained in the supernatant after centrifugation were determined using atomic absorption spectrometry. This supernatant contained only the released Ag ion portion of the incubated Ag-NPS, which was used as the Ag ion solution treatment. The morphology, characteristics, surface charge, and crystallinity of Ag-NPS were observed by using TEM (HITACHI, Ibaraki, Japan), energy-dispersive X-ray spectroscopy (EDX; EDAX, USA), X-ray photoelectron spectrometry (XPS; ESCALAB250Xi, USA), and X-ray diffraction (XRD; D/MAXTTRIII; CBO, Japan), respectively. The size distribution of Ag-NPs and PS-NPs suspended in deionized water and the zeta-potential were determined using a Malvern Zeta Sizer Nano ZS (Malvern Instruments, Malvern, UK).

\section{In vitro $B B B$ model establishment}

The primary rat microvascular endothelial cells, pericytes, and astrocytes were isolated and the in vitro biomimetic BBB was established as described in a previous study. ${ }^{18}$ The animal work was approved by the Nagasaki University Institutional Animal Care and Use Committee. The primary rat cells were collected according to the guidelines in the use of animals in Japan. The details for cell isolation, cell culture, and characterization of cell purity are described in a previous study. ${ }^{18}$ Briefly, pericytes were seeded in Transwell ${ }^{\circledR}$ membrane inverted cell culture inserts $\left(1.12 \mathrm{~cm}^{2}\right.$ for a 12 -well polycarbonate plate; Corning Incorporated, NY, USA). After 4 hours, primary brain endothelial cells were added to the luminal compartment of the inserts at a density of $2 \times 10^{6}$ cells $/ \mathrm{cm}^{2}$ having pericytes on the other side and positioned in the 12-well plates containing the astrocytes. The microvascular endothelial cells, pericytes, and astrocytes were cocultured in Dulbecco's Modified Eagle's Medium F-12 (with 10\% fetal bovine plasma derived serum). From Day 2, cells were grown in culture media containing $500 \mathrm{nM}$ hydrocortisone. Experiments were performed on Day 5. Transendothelial electrical resistance (TEER) was measured at days 2, 4, and 5 using a Millicell-ERS2 (Millipore, Billerica, MA, USA). Experiments were performed when TEER was $>200 \Omega \cdot \mathrm{cm}^{2}$. Previous research demonstrated that in vitro BBB models with TEER $>150 \Omega \cdot \mathrm{cm}^{2}$ give reasonable drug permeability results. ${ }^{19-21}$

\section{Cell treatments}

Ag-NPS $(1 \mu \mathrm{g} / \mathrm{mL}$ and $10 \mu \mathrm{g} / \mathrm{mL})$ and PS-NPs $(100 \mu \mathrm{g} / \mathrm{mL})$ were introduced into the Transwell ${ }^{\circledR}$ lumen at Day 5 of BBB model culture. After 24-hour treatment, TEER was measured using a Millicell-ERS2, and the Transwell ${ }^{\circledR}$ membrane (with microvascular endothelial cells and pericytes) and astrocytes were washed three times and cells were collected for confocal microscopy or TEM, respectively. These experiments were performed in triplicate wells.

For the DNA microarray experiment, Ag-NPS $(10 \mu \mathrm{g} / \mathrm{mL})$, Ag ions released from $10 \mu \mathrm{g} / \mathrm{mL}$ of Ag-NPS, and PS-NPs $(100 \mu \mathrm{g} / \mathrm{mL})$ were introduced into the Transwell ${ }^{\circledR}$ lumen. After 24 hours, astrocytes were collected for DNA microarray analysis. Briefly, astrocytes were washed three times using PBS, then digested with trypsin, and collected in Trizol solution for RNA extraction.

\section{TEM and immunostaining}

The Transwell ${ }^{\circledR}$ BBB model was exposed to Ag-NPS and PS-NPs for the concentrations and time durations indicated earlier. The Transwell ${ }^{\circledR}$ membrane and astrocytes were collected for TEM and immunostaining, respectively. The details of TEM were described in our previous study. ${ }^{22}$ A certified pathologist identified different cell organelles and Ag-NPs were identified according to their high density under TEM. For Confocal laser scanning microscopy of ZO-1 immunostaining, the secondary antibodies Alexa Fluor 488 conjugated anti-mouse immunoglobulins (Invitrogen, CA, USA) were used in a dilution 1:1000. To counter stain cell nuclei TO-PRO-3 Iodide (Invitrogen Corporation, CA, USA) was used in a dilution of 1:300. The immunostaining of the TJ protein ZO-1 was examined by a LSM5 PASCAL Zeiss confocal laser scanning microscope (Leica, Japan).

\section{Total RNA isolation and DNA microarray}

Total RNA was extracted from the collected astrocytes using the RNeasy reagent and the mini protocol for isolation of total RNA from animal cells (QIAGEN, Tokyo, Japan) according to the instructions provided by the manufacturer. The experimental details were described in our previous study. ${ }^{22}$ The DNA microarray experiment was conducted using Agilent 
G4130F Whole Rat Genome Microarray 4×44 K (Agilent, CA, US). To determine biologically relevant gene ontology (GO) terms (provided by the National Center for Biotechnology Information) of differentially expressed genes, the software "PANTHER" was used. It provides gene expression data analysis/comparison of gene lists (http://www.pantherdb.org/tools/ genexAnalysis.jsp). The analysis was performed using Unigene ID as the identifier for biological process categories.

\section{Quantitative real-time PCR}

Quantitative real-time PCR (SYBR Green method) for five selected genes ("test" genes) was performed to determine their gene expression levels and to verify the reliability of the microarray data. Primers used in this study are listed in Table 1. The details of the method were described in our previous study. ${ }^{22}$

\section{Results}

\section{$\mathrm{Ag}-\mathrm{NP}$ characterization}

The characterization of Ag-NPs used in this study was described in our previous study. ${ }^{23}$ The morphology of AgNPs in distilled water was observed using TEM (Figure 1A). The particle size distribution in distilled water was $7 \pm 2 \mathrm{~nm}$. The zeta potential was $-37.8 \pm 3.2 \mathrm{mV}$ in water. In cell culture medium, the particle size distribution was $101 \pm 12 \mathrm{~nm}$ and the zeta potential was $-7.9 \pm 0.6 \mathrm{mV}$. The XRD pattern of the Ag-NP showed the typical nature of the Ag-NP (data not shown). EDX results confirmed the presence of silver in cell culture medium (Figure 1B) and XPS results showed both $\operatorname{Ag}^{0}(81 \%)$ and $\operatorname{Ag}^{+}(19 \%)$ in the deposits of Ag-NPS diluted with cell culture media (Figure 1C), indicating that both Ag-NPs and Ag ions exist in the Ag-NPS. The silver ion content contained in $10 \mu \mathrm{g} / \mathrm{mL}$ of Ag-NPS (incubated for 24 hours, at $37^{\circ} \mathrm{C}$ ) occupied $1.1 \%$ of the total silver contents. The particle size distributions of PS-NPs in water and cell culture medium were $33 \pm 8 \mathrm{~nm}$ and $35 \pm 8 \mathrm{~nm}$, respectively.
The zeta potentials of PS-NPs in water and cell culture medium were $-29.6 \pm 2.6 \mathrm{mV}$ and $-8.93 \pm 0.16 \mathrm{mV}$, respectively.

\section{Characterization of isolated primary cells}

Primarily isolated rat brain microvascular endothelial cells grew into continuous monolayers and showed tightly arranged, nonoverlapping, elongated, and fusiform morphology. Microvascular endothelial cells were strongly positively immunostained for Factor VIII, an endothelial marker, indicating high purity of endothelial cells. Expression of TJ proteins, such as ZO-1 and Claudin-5, was observed by confocal microscopy, indicating the properties of BBB cells (Figure 2A). Astrocytes were polygonal with long cell processes, resembling astrocyte end feet, and strongly positive for glial fibrillary acidic protein staining (Figure 2B). Pericytes in culture spread large with irregular projections. The cells described herein were used to establish the in vitro BBB model. A schematic drawing of the in vitro BBB model is shown in Figure 3. Experiments were carried out on Day 5 when the TEER values of the BBB model were $>200 \Omega \cdot \mathrm{cm}^{2}$.

\section{Effect of Ag-NPS and PS-NPs on the TJ of the BBB}

The TEER values of the BBB in vitro model were all $>200 \Omega \cdot \mathrm{cm}^{2}$ before the experiment (Figure 4A). After 24-hour treatments, the PS-NP and Ag-NPS $(1 \mu \mathrm{g} / \mathrm{mL})$ groups did not change their TEER values significantly compared to control. However, the $10 \mu \mathrm{g} / \mathrm{mL}$ Ag-NPS group showed significantly decreased TEER values compared to control (Figure 4B). The immunostaining of the TJ protein ZO-1 of microvascular endothelial cells in the coculture BBB model showed a continuous, smooth, pericellular, belt-like pattern in the control and PS-NP groups. However, ZO-1 expression was apparently decreased in the $10 \mu \mathrm{g} / \mathrm{mL}$ Ag-NPS group compared to control (Figure 5), which was consistent with the TEER results.

Table I Primers used in the present study for real-time polymerase chain reaction

\begin{tabular}{lll}
\hline Gene & GeneBank & Primary sequence 5'-3' \\
\hline Txnip & NM_001008767 & Forward primer: GGAGAAAGTTCTGCTCTCG \\
Ddit4 & NM_080906 & Reverse primer: AAGTGCTAAGGCGGAGTAA \\
Nr4al & Forward primer: TAACACCAGGGAGCTGC \\
& NM_024388 & Reverse primer: ACAGTTCACTCCTCCAGTACA \\
Egr2 & Forward primer: ATCTCTTCCGCTCTCCT \\
Fos & NM_053633 & Reverse primer: ATCAGAATCTGTCAATCACCT \\
& NM_022I97 & Forward primer: TTATTAGCTCTTAATAGTTGTGGAAA \\
& & Reverse primer: CTGAACTCCAGTTAGTGGT \\
\hline
\end{tabular}


A

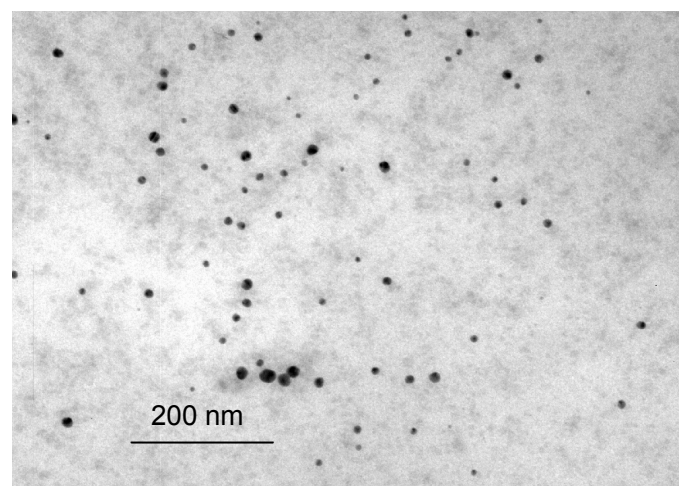

B

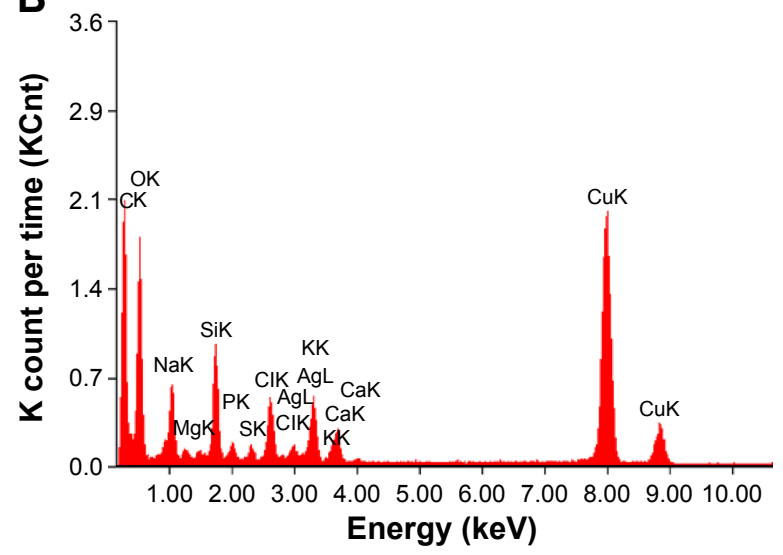

C

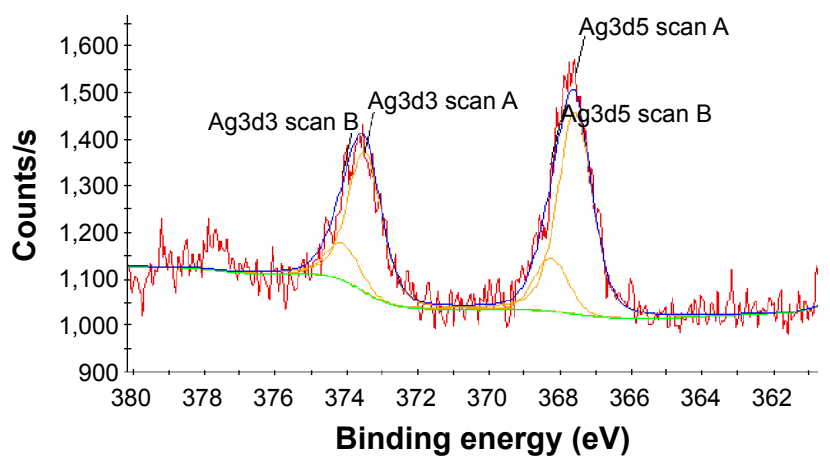

Figure I Characterization of Ag-NP.

Notes: (A) TEM image of Ag-NPs in distilled water. (B) EDX of Ag-NPS in cell culture media. (C) XPS analysis of Ag-NPS in cell culture media. The experiments were performed by using the deposits of Ag-NP/cell culture medium suspension.

Abbreviations: Ag-NP, silver nanoparticle; Ag-NPS, Ag-NP suspension; EDX, energy-dispersive X-ray spectroscopy; TEM, transmission electron microscopy; XPS, X-ray photoelectron spectrometry.

\section{Effects of Ag-NPS and PS-NPs on the ultrastructural changes of the BBB}

TEM images showed that microvascular endothelial cells formed the TJs very well in the in vitro BBB model (Figure 6Aa), and pericytes spread large with irregular projections on the other sides of the Transwell ${ }^{\circledR}$ membrane in the control group (Figure 6Ba). In PS-NP group, no significant TJ disruptions were observed between microvascular endothelial cells (Figure 6Ab). No ultrastructural changes were observed in the pericytes (Figure 6Bb). In the $1 \mu \mathrm{g} / \mathrm{mL}$ Ag-NPS group, discontinuous TJs were not observed. Vacuolations and endoplasmic reticulum (ER) expansion were occasionally observed in the microvascular endothelial cells (Figure 6Ac and d). Vacuolations were also occasionally observed in pericytes (Figure 6Bc). In the $10 \mu \mathrm{g} / \mathrm{mL} \mathrm{Ag-NPS} \mathrm{group,}$ Ag-NP-like nanoparticles were observed inside the endothelial cells and pericytes. Apart from discontinuous TJ, ER expansion, vacuolations, and mitochondrial shrinkage were also observed (Figure 6Ae and f). Vacuolations were observed in pericytes in the $10 \mu \mathrm{g} / \mathrm{mL} \mathrm{Ag-NPS} \mathrm{group} \mathrm{(Figure} \mathrm{6Bd).}$

\section{Effects of Ag-NPS on the ultrastructural changes of astrocytes}

Astrocytes did not show significant cytotoxicity, such as morphological changes and damages in all treatment groups compared to the control, as observed by light microscopy (data not shown). TEM images showed that astrocytes grew with normal morphology in the control group (Figure 6Ba). In the PS-NP and $1 \mu \mathrm{g} / \mathrm{mL}$ Ag-NPS groups, no ultrastructural changes were observed in astrocytes in most images, and mitochondrial shrinkage was observed occasionally (Figure 6Bb and c). In the $10 \mu \mathrm{g} / \mathrm{mL}$ Ag-NPS group, severe mitochondrial shrinkage was observed (Figure 6Bd) and nuclear atypia was observed occasionally (Figure 6Be). Meanwhile, Ag-NP-like particles appeared inside astrocytes (Figure 6Bf).

\section{Global gene expression changes}

Filtering of the array results was done for astrocytes as follows: genes were considered to be upregulated or downregulated when the relative expression levels $\left[\log _{2}\right.$ (gene expression ratio of treated/control)] differed by $>1$ or less 

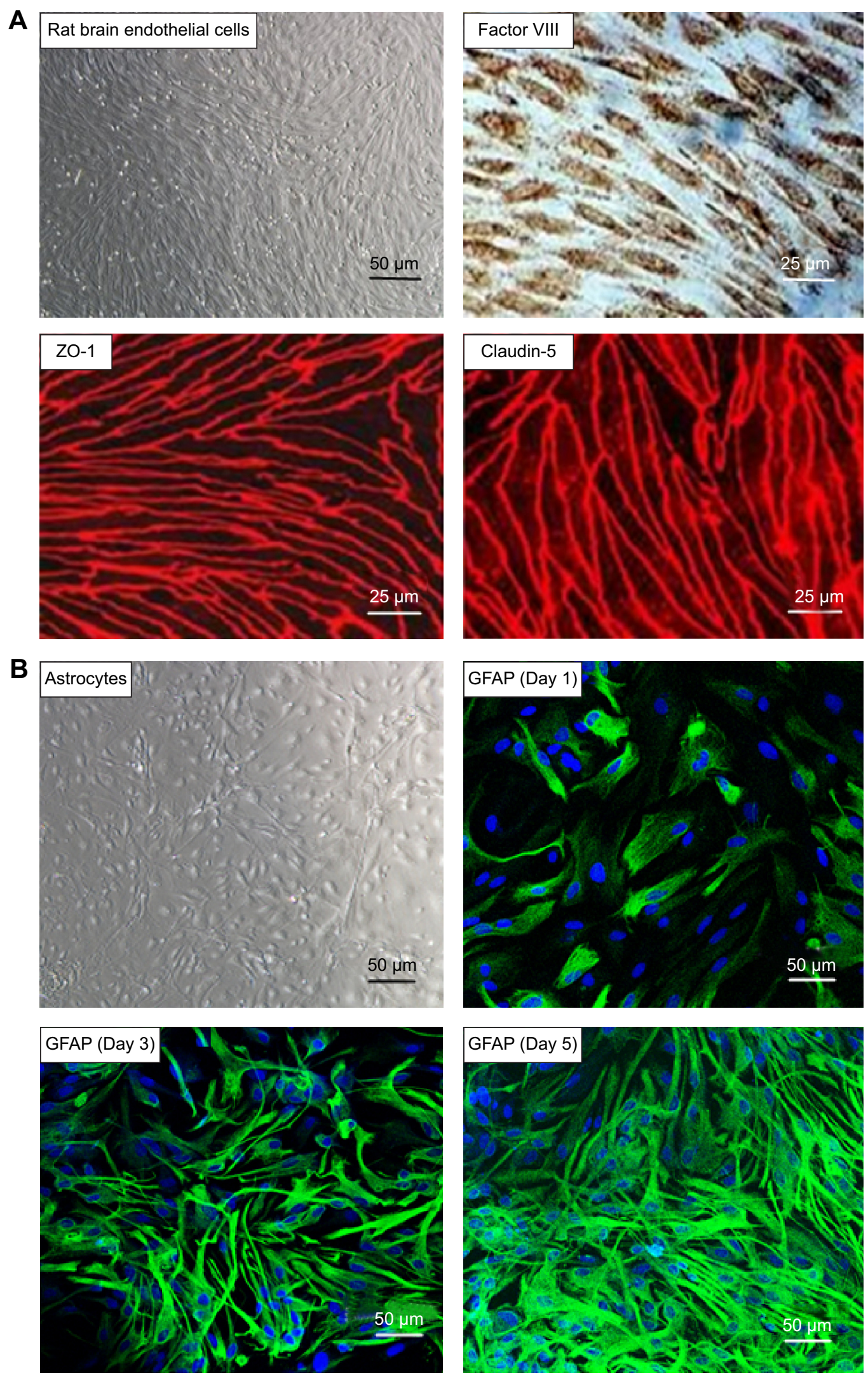

Figure 2 Characterization of primary rat brain microvascular endothelial cells.

Notes: (A) Primary rat brain microvascular endothelial cells form a pure, near-confluent monolayer by light microscopy (upper left panel). Factor VIII (a marker for endothelium; red), ZO-I, and Claudin-5 (tight junction proteins; red) expressions are positive in primary rat brain microvascular endothelial cells by confocal microscopy. (B) Characterization of primary astrocyte cultures in different confluence culture condition by light microscopy (upper left panel) and confocal microscopy. Astrocytes are positive for GFAP.

Abbreviation: GFAP, glial fibrillary acidic protein 


\section{A}
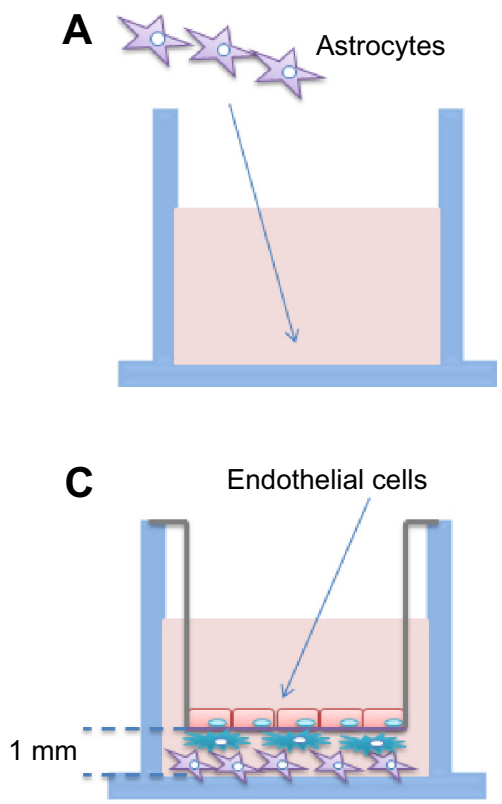

B

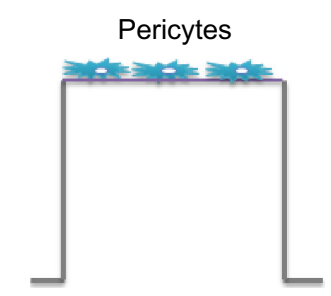

D

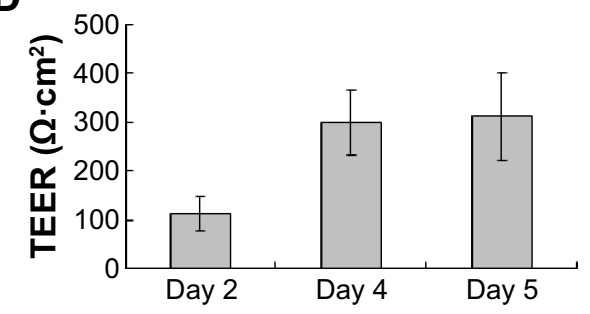

Figure 3 Schematic drawing of the preparation of the in vitro blood-brain barrier model.

Notes: (A) Rat astrocytes were seeded at the bottom of I2-well plates, while (B) rat brain pericytes were seeded at the against-lumen side of Transwell ${ }^{\circledast}$ membranes of inverted cell culture inserts. After 4 hours, (C) endothelial cells were seeded into the luminal compartment of the inserts having pericytes on the other side and positioned into the 12 well plates containing the astrocytes. (D) TEER (expressed as $\Omega \cdot \mathrm{cm}^{2}$ ) of the blood-brain barrier model, measured on different days. Data are presented as mean \pm SD ( $\mathrm{n}=3$ ). Abbreviations: SD, standard deviation; TEER, transendothelial electrical resistance.

than -1 in treated groups $(10 \mu \mathrm{g} / \mathrm{mL} \mathrm{Ag-NPS}$ or released $\mathrm{Ag}$ ion or $100 \mu \mathrm{g} / \mathrm{mL}$ PS-NP) compared to control. We observed that 23 genes in total were differentially expressed in the $10 \mu \mathrm{g} / \mathrm{mL}$ Ag-NPS-treated group compared to control. Of the 23 genes, there were 20 downregulated genes and 3 upregulated genes in astrocytes (Table S1). Sixteen genes in total were differentially expressed in the released Ag ion-treated group compared to control, and there were 15 downregulated genes and 1 upregulated gene (Table S2).

By comparing the gene expression profiles of astrocytes exposed to Ag-NPS or their released Ag ions (Tables S1A, S1B, S2A, and S2B), we observed a total of nine genes (eight genes downregulated and one gene upregulated) that were changed in common, suggesting that changes in these genes are attributable to the released Ag ions. This implies that 2 genes from the total of 3 upregulated genes and 12 genes from the total of 28 downregulated genes were uniquely induced by Ag-NPs, not released Ag ions. Furthermore, the upregulated genes in common showed a higher expression level in the Ag-NPS treatment group than in the released Ag ion group. The downregulated genes (nuclear receptor subfamily 4, group A, member 1 [Nr4al], early growth response 2 [Egr2], protein kinase KID2 [kid2], nuclear receptor subfamily 4 , group $\mathrm{A}$, member 3 [Nr4a3], and
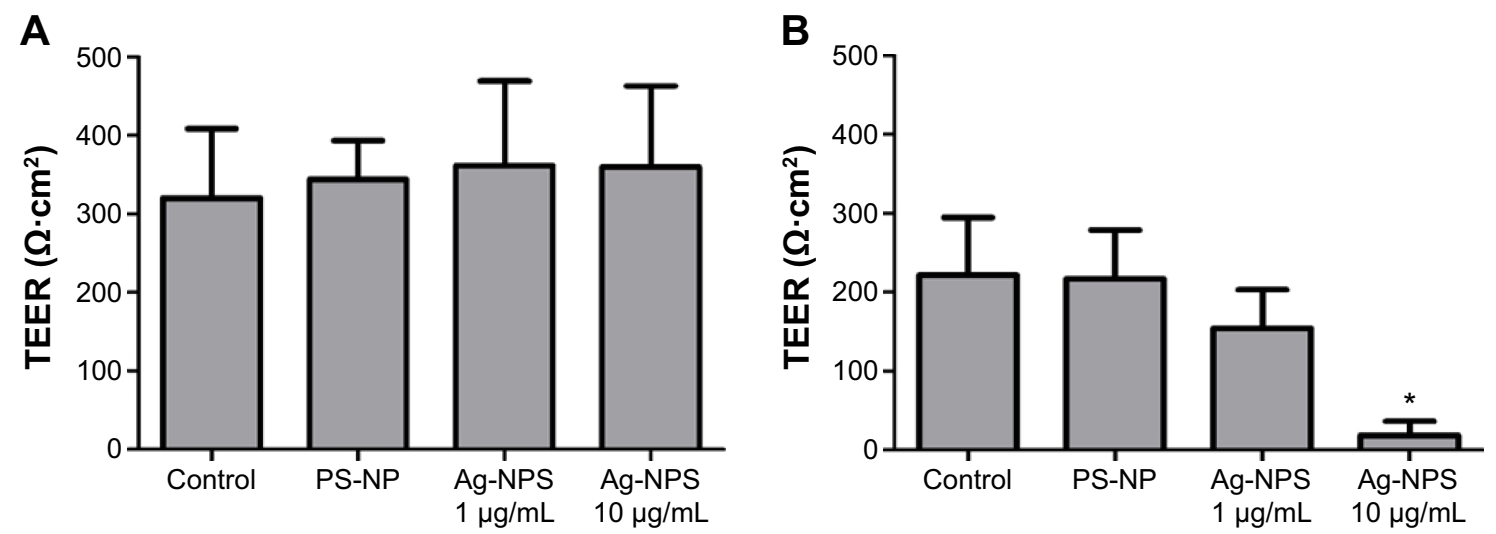

Figure 4 The effect of Ag-NPS and PS-NP on BBB permeability measured by TEER.

Notes: TEER (expressed as $\Omega \cdot \mathrm{cm}^{2}$ ) of the BBB model (A) before and (B) after 24 hours' treatment in control, PS-NP (I00 $\left.\mu g / \mathrm{mL}\right)$, and Ag-NPS (I $\mu \mathrm{g} / \mathrm{mL}$ and I0 $\left.\mu \mathrm{g} / \mathrm{mL}\right)$ groups. All data are presented as mean \pm SD. *Significant difference compared to the control $(P<0.05)$.

Abbreviations: Ag-NPS, silver nanoparticle suspension; BBB, blood-brain barrier; PS-NP, polystyrene nanoparticle; SD, standard deviation; TEER, transendothelial electrical resistance. 

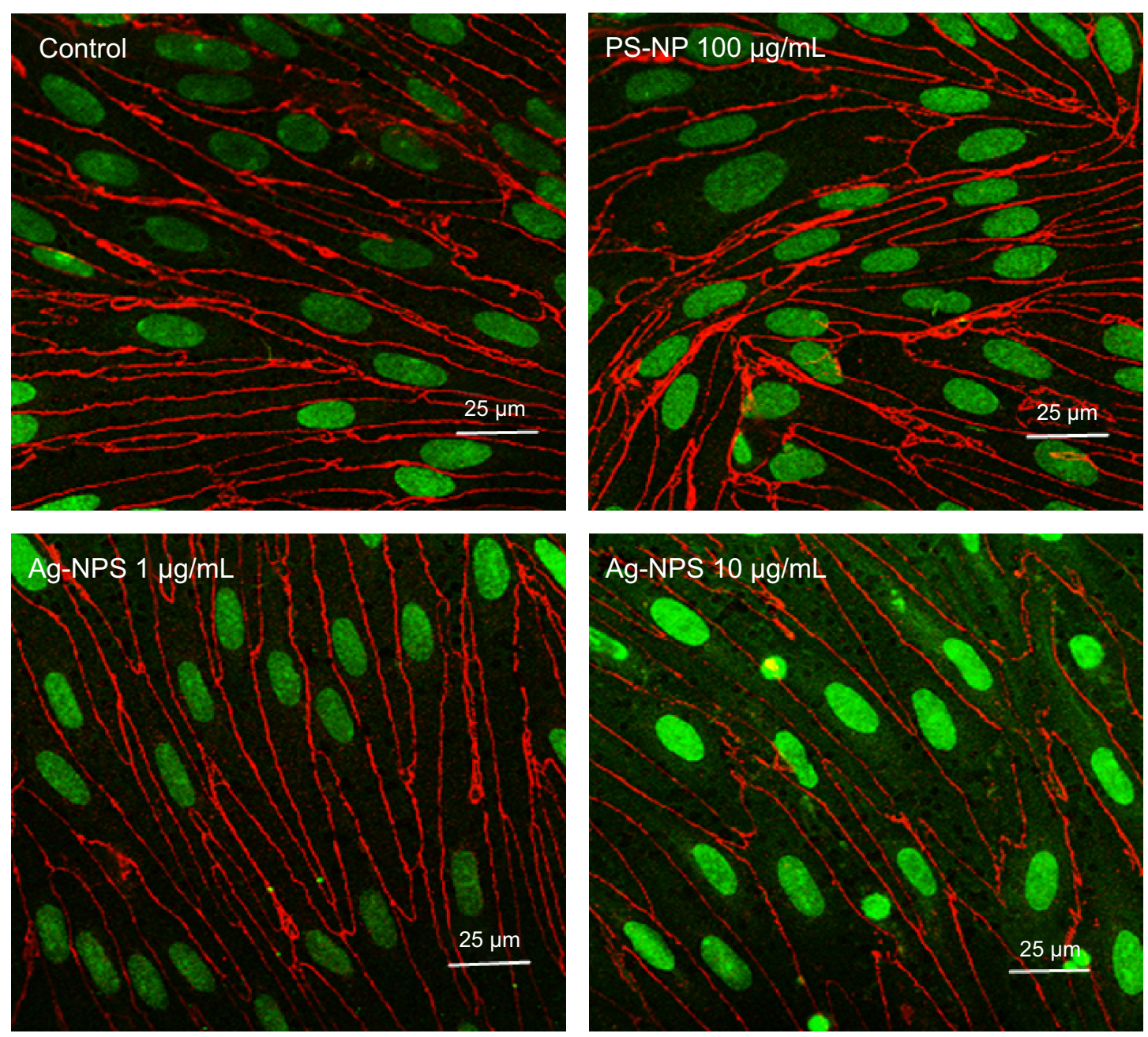

Figure 5 Immunofluorescent staining of tight junction protein ZO-I (red) in confluent brain endothelial cell in triple coculture.

Notes: The ZO-I immunostaining of endothelial cells in coculture shows a continuous, smooth, pericellular, belt-like pattern in control and PS-NP groups. However, ZO-I immunostaining was significantly decreased in the $10 \mu \mathrm{g} / \mathrm{mL} \mathrm{Ag-NPS}$ group compared to the control.

Abbreviations: Ag-NPS, silver nanoparticle suspension; PS-NP, polystyrene nanoparticle.

activity-regulated cytoskeleton-associated protein $[A r c]$ ) showed a greater extent of decreases in the Ag-NPS group compared with the levels in the released Ag ion group. The other three downregulated genes (protein sprouty homolog 1 [spry1], dual specificity phosphatase 5 [Dusp5], and chemokine (C-X-C motif) ligand $1[\mathrm{Cxcll}])$ have similar changes in both $\mathrm{Ag}-\mathrm{NPS}$ and Ag ion groups. These results indicate that the toxic responses observed in Ag-NPS-exposed astrocytes are attributable to both Ag-NPs and their released Ag ions. Ag-NPS caused higher gene expression changes compared with their released Ag ion group, suggesting a synergistic toxic effect induced by Ag-NPS and their released Ag ions.

\section{Pathway analysis}

To further investigate the molecular mechanism of Ag-NPSinduced cellular responses, GO and Kyoto Encyclopedia of Genes and Genomes (KEGG) molecular pathway analyses were performed. In the $10 \mu \mathrm{g} / \mathrm{mL}$ Ag-NPS-treated group, 139 biological functions were changed based on GO (Table S3), which were associated with metabolic processes, biosynthetic processes, response to stimuli stimulus, developmental processes, regulation of molecular function, biological processes, transcription, regulation of signaling, cell death, gene expression, learning, memory, and behavior (Figure 7). The MAPK signaling pathway was significantly changed in KEGG pathway analysis, which was linked to four genes (Dusp1, Dusp5, FBJ osteosarcoma oncogene [Fos], and $\mathrm{Nr} 4 a \mathrm{l}$ ). However, no GO and KEGG pathways were changed in the released $\mathrm{Ag}$ ion-treated group and PS-NP-treated group.

\section{Quantitative real-time PCR determination}

To determine the gene expression level and verify the reliability of differentially expressed genes identified by the 
A
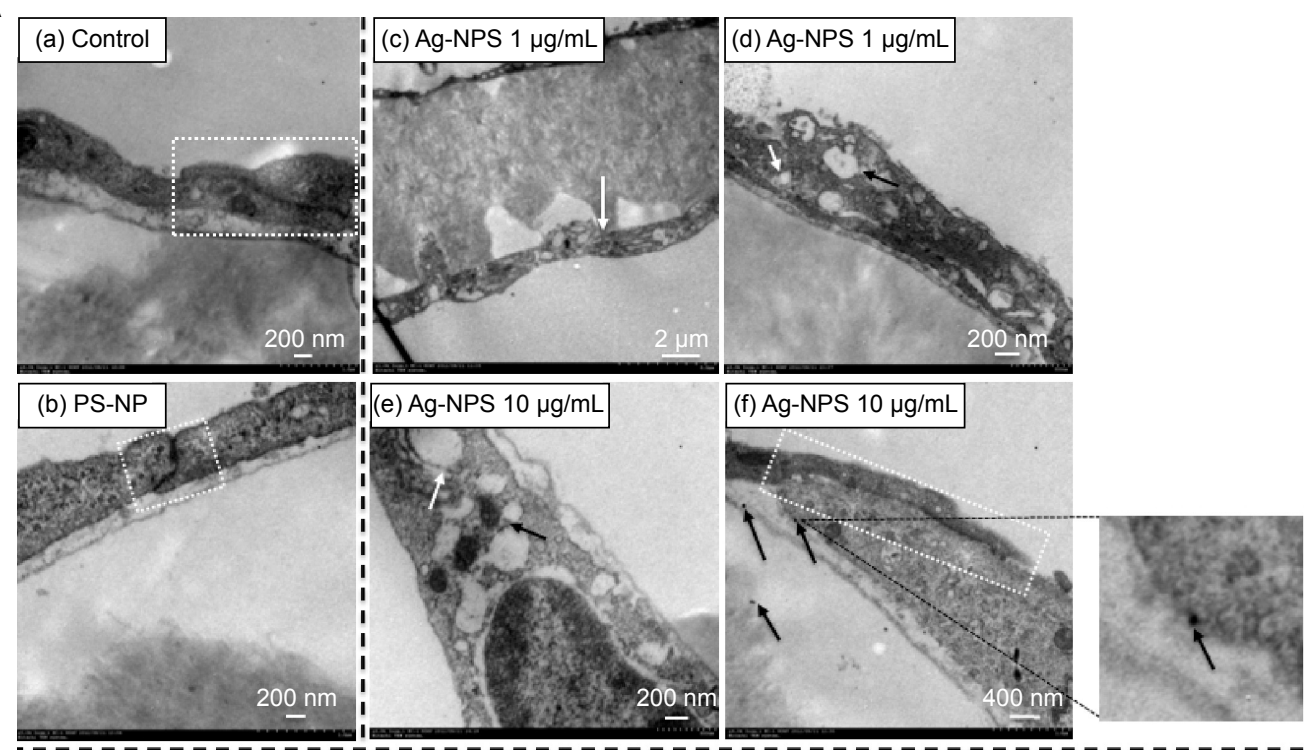

B
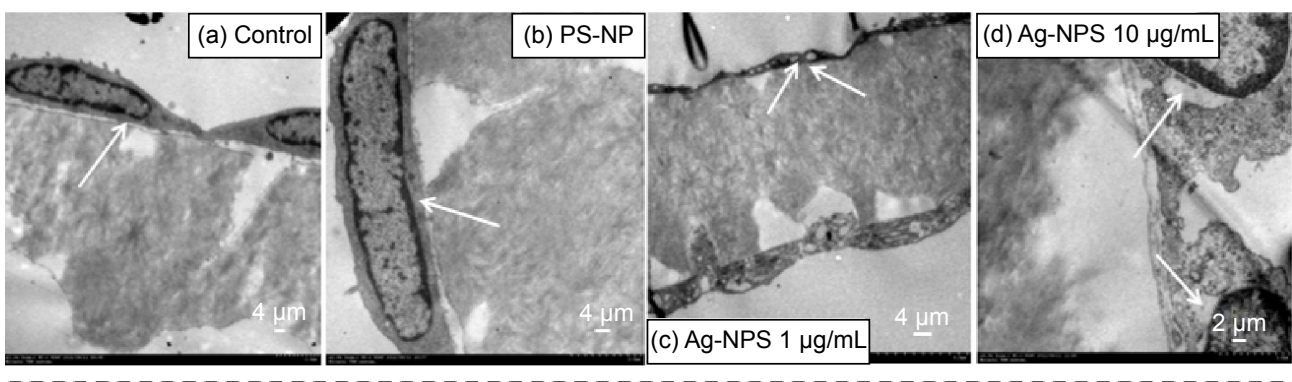

C
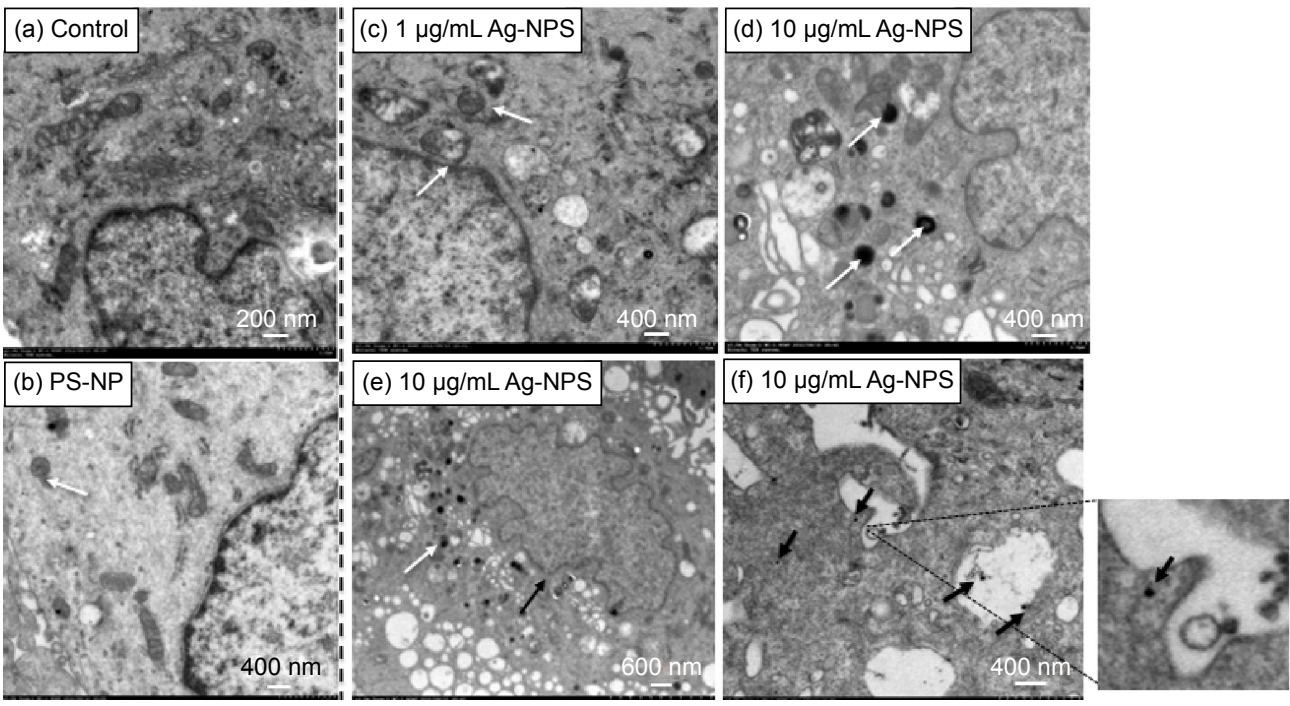

Figure 6 TEM images of primary rat brain (A) microvascular endothelial cells, (B) pericytes, and (C) astrocytes after 24-hour treatments.

Notes: (A) In the control group, endothelial cells form TJs (a, white dash box). In the PS-NP group, a TJ (b, white dash box) between endothelial cells was not disrupted. In the I $\mu \mathrm{g} / \mathrm{mL}$ Ag-NPS group, the endothelial cells grew nicely on the membrane (c, white arrow) and discontinuous TJs were not observed. Vacuolations (d, white arrow) and ER expansion (d, dark arrow) were observed in the endothelial cells. In the $10 \mu \mathrm{g} / \mathrm{mL}$ Ag-NPS group, mitochondrial shrinkage (e, dark arrow) and ER expansion (e, white arrow) appeared; Discontinuous TJs (f, white dash box) and Ag-NP-like particles as showed in the insert for (f) (f, dark arrows) in endothelial cells were observed. (B) Pericytes grew nicely on the other side of the membrane (white arrow) in the control group (a) and PS-NP group (b). In the I $\mu g / \mathrm{mL}$ Ag-NPS group, vacuolations (white arrows) were observed occasionally in pericytes (c). In the $10 \mu \mathrm{g} / \mathrm{mL}$ Ag-NPS group, vacuolations (white arrows) were observed in pericytes (d). (C) In the control group, astrocytes had normal cell morphology (a). In the PS-NP group, mitochondrial shrinkage was observed occasionally (white arrow) (b). In the I $\mu$ g/mL Ag-NPS group, mitochondrial shrinkage was occasionally observed (white arrows) (c). In the $10 \mu \mathrm{g} / \mathrm{mL}$ Ag-NPS group, nuclear atypia (black arrows) and severe mitochondrial shrinkage (white arrows) were observed ( $\mathrm{d}$ and e); Ag-NP-like particles (showed in the insert for $\mathrm{f}$ ) were also observed in astrocytes (f, black arrows), as well as in the enlarged picture.

Abbreviations: Ag-NPS, silver nanoparticle suspension; ER, endoplasmic reticulum; PS-NP, polystyrene nanoparticle; TEM, transmission electron microscopy; TJ, tight junction. 


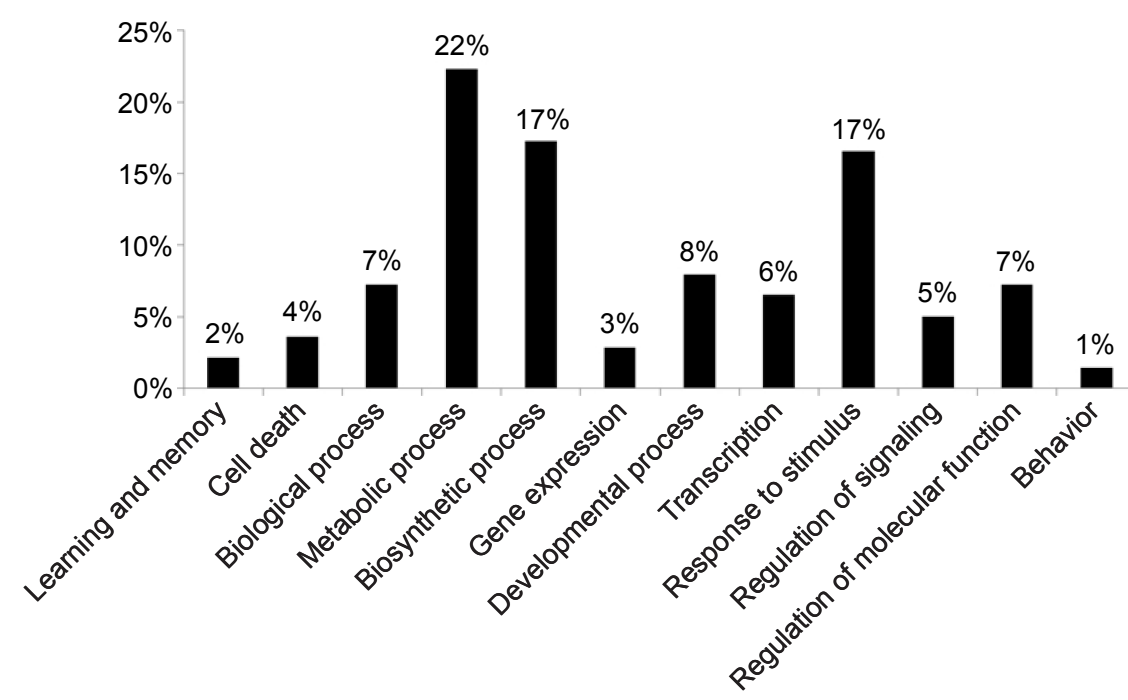

Figure 7 Functional classification (GO terms) of differentially expressed genes based on GO.

Notes: The data were collected from astrocytes exposed to $10 \mu \mathrm{g} / \mathrm{mL}$ of Ag-NPS for 24 hours. The percentage of related GO terms for each category is indicated. Percentage $(\%)=$ (related GO terms for each category/related GO terms for all categories) $\times 100 \%$.

Abbreviations: Ag-NPS, silver nanoparticle suspension; GO, gene ontology.

DNA microarray, five genes selected from the groups of up- and downregulated genes after exposure to Ag-NPS and released Ag ions were further examined using quantitative real-time PCR. Thioredoxin interacting protein-encoding gene (Txnip) and DNA damage inducible transcript 4 (Ddit4) were upregulated, while Nr4a1, Egr2, and Fos were downregulated in both reverse transcriptase-PCR and DNA microarray (Table 2).

\section{Discussion}

Nanoparticles have been increasingly used in medicine, cosmetics, electronics, and food additives. However, the influence of nanoparticles on human health and brain has not been studied well. ${ }^{24}$ Several studies have demonstrated that Ag-NPs can enter the $\mathrm{CNS}^{25}$ and induce brain edema and neurotoxicity. ${ }^{10,11,26-29}$ Our previous studies showed that Ag-NPS and/or released Ag ions crossed the BBB and subsequently caused damage to astrocytes and neurons. ${ }^{23}$ Cadherin and claudin expression were slightly changed in the Ag-NPS-exposure group, and astrocyte swelling was the most significant change after a 2-week gastrointestinal exposure to $1 \mathrm{mg} / \mathrm{kg}$ or $10 \mathrm{mg} / \mathrm{kg}$ of Ag-NPS in rats. Furthermore, Ag-NPs interacting with the cerebral microvasculature can induce formation of reactive oxygen species (ROS) and proinflammatory mediators, which can increase BBB permeability. ${ }^{7-9,11}$ However, the biological effects of Ag-NPs on the $\mathrm{BBB}$ and brain are still unclear. It is critical to further understand the toxicity of Ag-NPS using a biomimic BBB model. In the present study, we demonstrated for the first time the toxic responses and mechanisms of Ag-NPS by observing the ultrastructure and gene expression profile changes using a biomimetic BBB model (microvascular endothelial cells/ pericytes/astrocytes).

In the current study, we established a primary $\mathrm{BBB}$ triple coculture model. The model used primary rat brain microvascular endothelial cells, pericytes, and astrocytes corresponding to the anatomical situation in brain capillaries. Previous research showed that pericytes contributed to the

Table 2 RT-PCR validation of selected genes from microarray data

\begin{tabular}{|c|c|c|c|c|}
\hline \multirow[t]{2}{*}{ Gene } & \multicolumn{2}{|l|}{ Ag-NPS } & \multicolumn{2}{|l|}{$A g$ ion } \\
\hline & $\begin{array}{l}\text { RT-PCR } \\
(\text { mean } \pm \text { SE)* }\end{array}$ & $\begin{array}{l}\text { Microarray } \\
\left(\log _{2}\right)^{\#}\end{array}$ & $\begin{array}{l}\text { RT-PCR } \\
(\text { mean } \pm \text { SE)* }\end{array}$ & $\begin{array}{l}\text { Microarray } \\
\left(\log _{2}\right)^{\#} \\
\end{array}$ \\
\hline Txnip & $4.20 \pm 0.16$ & 1.836 & $2.32 \pm 0.10$ & 1.109 \\
\hline Ddit4 & $2.87 \pm 0.15$ & I.58| & $1.94 \pm 0.12$ & 0.883 \\
\hline $\mathrm{Nr} 4 a \mathrm{l}$ & $0.03 \pm 0.00$ & -3.463 & $0.35 \pm 0.14$ & -1.982 \\
\hline Egr2 & $0.08 \pm 0.01$ & -2.898 & $0.43 \pm 0.12$ & -1.292 \\
\hline Fos & $0.29 \pm 0.02$ & -1.462 & $0.97 \pm 0.13$ & -0.192 \\
\hline
\end{tabular}

Notes: *Mean \pm SE; experiment was performed in triplicate; ${ }^{~} \log _{2}=\log _{2}$ (gene expression ratio of Ag-NPS or Ag ion/Control).

Abbreviations: Ag-NPS, Ag-NP suspension; RT-PCR, reverse transcriptase polymerase chain reaction; SE, standard error. 
maturation and maintenance of $\mathrm{BBB}$ properties $\mathrm{s}^{30}$ and there was a clear correlation between a higher ratio of pericytes versus endothelial cells in blood vessels and the tightness of the endothelial barrier. ${ }^{31}$ Furthermore, astrocytes can decrease the paracellular permeability of immortalized rat brain endothelial cells. ${ }^{32}$ In the present study, the high expression of TJ proteins and the high TEER demonstrated that the triple coculture model is among the best primary $\mathrm{BBB}$ models to mimic the $\mathrm{BBB}$ in vivo. ${ }^{33}$ This primary $\mathrm{BBB}$ model provides a very useful in vitro model to evaluate the effect of vasculotoxic or vasculoprotective agents on the BBB. In this study, this triple coculture model was used to investigate the changes to BBB integrity and the molecular mechanisms in vitro following exposure to Ag-NPS.

As mentioned herein, several studies showed that Ag-NPs can disrupt the BBB and cause CNS toxicity. However, the toxicological effects of Ag-NPs on the typical biomimetic $\mathrm{BBB}$ are still uncertain. In the present study, $10 \mu \mathrm{g} / \mathrm{mL}$ Ag-NPS showed significant effects on BBB permeability and TJ protein expression, whereas $1 \mu \mathrm{g} / \mathrm{mL}$ Ag-NPS did not. Vacuolations were also observed by TEM in pericytes after Ag-NPS exposure. Previous studies demonstrated that pericyte deficiency or dysfunction leads to chronic $\mathrm{BBB}$ damage and contributes to neurodegeneration during Alzheimer's disease pathogenesis. ${ }^{34-36}$ Further studies are needed to investigate whether Ag-NPS can cause pericyte dysfunction and potential neuronal injury. We further observed a large amount of mitochondrial shrinkage and ER extension, as well as Ag-NP-like particles, in astrocytes by TEM, which demonstrated that Ag-NPs entered astrocytes and induced toxicity after crossing the endothelial cells and pericytes.

To identify the molecular mechanisms of multiple genes working together following exposure to Ag-NPS, released Ag ions, and PS-NPs, microarray assays of astrocytes were performed to establish a global gene expression profile. The functional classification of these genes was analyzed using GO. Our results demonstrated that the toxicological effects on astrocytes were significantly different between the Ag-NPS and the released Ag ion or PS-NP group. In contrast with the Ag-NPS-treated group that showed induction of $139 \mathrm{GO}$ and 1 KEGG pathway genes, no GO term and KEGG pathway gene was changed in the released-ion or PS-NP exposure group. The expression levels of 16 genes were changed after exposure to released $\mathrm{Ag}$ ions, but the fold changes were less in general compared with the changes in the Ag-NPS treatment group (Table S3). The results were consistent with our previous research, which showed that Ag-NPS induced greater toxicity compared with the released Ag ions. The greater toxicity was attributed to the Ag-NPS. Ag-NPs, as heavy metal nanoparticles, but not the characteristics of a nano-sized particle themselves (as do PS-NP), caused severe toxicity in astrocytes.

Ag-NPs have been demonstrated to induce oxidative stress and apoptosis in the brain. ${ }^{37}$ The effects of $25 \mathrm{~nm} \mathrm{Ag-NPs} \mathrm{on}$ gene expression were evaluated in different regions of the mouse brain. Ag-NPs produced apoptosis and neurotoxicity by generating free radical-induced oxidative stress. The oxidative stress induced by Ag-NPs in the brain was also related to reduction of antioxidant capacity. Ag-NPs altered expression of genes such as Txnip, which is a member of the $\alpha$-arrestin family involved in redox sensing and metabolic control. ${ }^{38}$ Our data in Tables S1 and S2 obtained from realtime PCR showed that Txnip was significantly upregulated 4.20-fold and 2.32-fold in the Ag-NPS and Ag ion treatment groups, respectively. Upregulation of Txnip modulates antioxidant defense by inhibiting the Trx system and increasing ROS and oxidative stress. ${ }^{39}$ Txnip also upregulated the transcription factor NF- $\kappa \mathrm{B}$, which induces transcription of proinflammatory cytokines such as tumor necrosis factor- $\alpha$ and interleukin-1 $\beta .{ }^{40}$ These two pathways can further activate the apoptotic MAPK pathway, leading to cell death. ${ }^{41}$ Ag-NPs also activated the p38 MAPK pathway, causing apoptosis of Jurkat T cells. ${ }^{42}$ In the present study, Ag-NPS also induced Ddit4 expression. This was not produced by the released $\mathrm{Ag}$ ions. Ddit4 is known to inhibit mTOR activity, resulting in an increase in apoptosis in mouse embryonic fibroblasts. ${ }^{43}$ Ddit4 can reduce cell proliferation, growth, and maturation by inhibiting mTOR-mediated synthesis of proteins. ${ }^{44}$ Furthermore, in our study, five functional GO molecule annotations (nine genes) were involved in apoptosis/cell death only after Ag-NPS exposure. For example, $\mathrm{Nr} 4 \mathrm{al}$, encoding an orphan nuclear receptor for neural apoptosis, was the most downregulated gene in astrocytes. $\mathrm{Nr} 4 a \mathrm{l}$ has been implicated in apoptosis, ${ }^{45}$ cell survival, and metabolism. ${ }^{46} \mathrm{Nr} 4 a \mathrm{l}$ can be induced after excitotoxic and oxidative stress in neurons, and it upregulates neuroprotective genes and increases neuronal survival. $\mathrm{Nr} 4 \mathrm{al}$ also has early protective function in neural cells/tissues against various pathophysiological stresses. ${ }^{47}$ In this study, Ag-NPS induced downregulation of $\mathrm{Nr} 4 \mathrm{al}$ in the astrocyte, which could decrease the neuroprotective function against oxidative stress. Ag-NPS exposure also reduced B-cell lymphoma 2 ( $\mathrm{Bcl}-2)$ expression, which is present in the inner mitochondrial membrane and plays an important role in regulation of ROS production and apoptosis. A previous study showed that oxidative stress reduced $\mathrm{Bcl}-2$ 
expression, indicating onset of apoptosis in zebrafish brain. ${ }^{48}$ Dusp1 can mediate MAPK signaling and inflammation. ${ }^{49}$ The downregulation of Duspl in the Ag-NPS treatment group activates the MAPK signaling pathway, which induces inflammation and apoptosis. KEGG pathway analysis also showed that the MAPK signaling pathway was affected in astrocytes after exposure to Ag-NPS, but not after exposure to released $\mathrm{Ag}$ ions. In general, compared with released $\mathrm{Ag}$ ions, Ag-NPS induced more toxicity by generating ROS and significantly decreasing the expression of neuroprotective genes against ROS in astrocytes, weakening astrocytes' ROS protective ability, and subsequently inducing inflammation and apoptosis. Taken together, our results were consistent with previous research, ${ }^{50}$ which showed that ROS generation, inflammatory reactions, and apoptosis are the primary mechanisms of Ag-NP induced toxicity. ${ }^{19,48}$

Previous research has demonstrated that astrocytes play an important role in providing polyunsaturated fatty acids to the BBB and brain. ${ }^{51}$ Polyunsaturated fatty acids are ROS targets in the brain due to their high metabolic rate and their rich composition in the brain, ${ }^{52}$ which make astrocytes more sensitive to Ag-NP-induced ROS and more susceptible to losing their defense ability. In the present study, antioxidant defense was inhibited in astrocytes following Ag-NPS exposure. Meanwhile, Ag-NPS also induced inflammation and apoptosis through the MAPK pathway, Bcl-2 expression, or mTOR activity in astrocytes. The results raise concerns regarding Ag-NP toxicity in astrocytes. More studies are needed to understand how the toxicity effects induced by Ag-NPs in astrocytes influence neuron functions.

In the present study, 3 learning/memory/cognition processes, 11 developmental processes, 31 metabolic processes, and 24 biosynthetic processes were affected in astrocytes after Ag-NPS exposure (Table S3). Our results are consistent with previous studies that demonstrated that Ag-NPs can reduce learning and cognition of rats $^{53}$ and can produce developmental neurotoxicity and behavioral effects. ${ }^{54}$ Furthermore, the metabolic relationship between astrocytes and neurons is critical for energy metabolism and the synthesis of neurotransmitters. ${ }^{55}$ We speculate that induction of a large amount of changes in metabolic processes of astrocytes by Ag-NPS could significantly influence neuronal functions. Astrocytes also release factors that sustain neuronal function and viability. Astrocytes synthesize and secrete a wide range of neurotrophic and growth factors, cytokines, extracellular matrix proteins, proteoglycans, and cholesterol, which are involved in neuronal survival, proliferation, differentiation, and synaptogenesis. ${ }^{56} \mathrm{Ag}$-NPS exposure significantly inhibited biosynthetic processes in

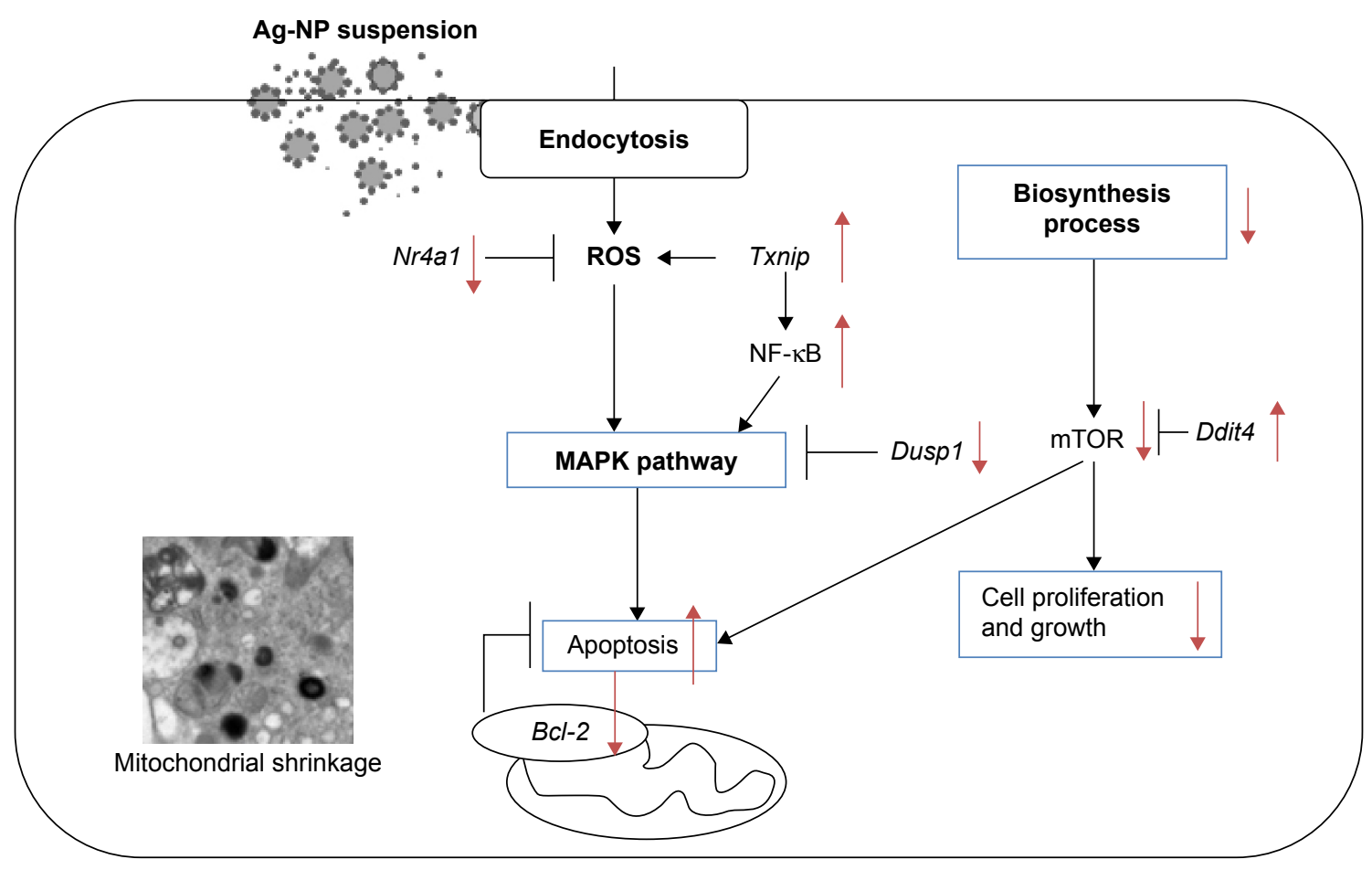

Figure 8 Mechanisms of neurotoxicity induced by Ag-NPS in astrocytes based on the data from the present investigation. Abbreviations: Ag-NPS, silver nanoparticle suspension; Bcl-2, B-cell lymphoma-2; ROS, reactive oxygen species; Txnip, thioredoxin interacting protein. 
astrocytes and may decrease the secretion of important nutrients and signal factors. Further studies are needed to investigate how the toxicity effects induced by Ag-NPs in astrocytes influence neuronal survival, proliferation, and differentiation to better understand the mechanisms of AgNP-induced neurotoxicity.

\section{Conclusion}

We established a BBB model using microvascular endothelial cells, pericytes, and astrocytes, which enhanced levels of TJ proteins (claudin-5 and ZO-1), with TEER $>200 \Omega \cdot \mathrm{cm}^{2}$ on Day 5. After $10 \mu \mathrm{g} / \mathrm{mL}$ Ag-NPS exposure for 24 hours, the BBB permeability was significantly increased and ZO-1 expression was significantly decreased compared to control. Severe mitochondrial shrinkage, ER expansion, and nuclear atypia were observed in astrocytes. Global gene expression analysis showed 23 significantly changed genes that were associated with several biological processes. As illustrated in Figure 8, Ag-NPS significantly increased Txnip expression, which modulated antioxidant defense. On the other hand, Ag-NPS significantly decreased Nr4al and Duspl, which protect cells from oxidative stress, inflammation, and apoptosis. Ag-NPS induced toxicity by decreasing antioxidant defense in astrocytes. Meanwhile, Ag-NPS also induced ROS, inflammation, and apoptosis through modulation of the MAPK pathway or Bcl-2 expression or mTOR activity in astrocytes. Ag-NPS also inhibited eleven developmental processes and caused learning and cognition reduction. Furthermore, Ag-NPS significantly suppressed 31 metabolic and 24 biosynthesis processes in astrocytes, which may influence the main function of astrocytes in the CNS and increase the risk of Ag-NPinduced neurotoxicity.

\section{Acknowledgments}

The authors gratefully acknowledge Dr Chunying Chen and Dr Ru Bai (National Center for Nanoscience and Nanotechnology, People's Republic of China), for their technical support for EDX and XPS characterization of silver nanoparticles, and Dr Chang Shi (Beijing Institute of Pharmacology and Toxicology, National Beijing Center for Drug Safety Evaluation and Research, People's Republic of China) for her feedback.

This study was financially supported by the Beijing Natural Science Foundation of China (\#3112024); National Natural Science Foundation of China (\#81401517); National Key Technology Research and Development Program of the Ministry of Science and Technology of China
(\#2012BAK26B00); Principal Scientists Training Fund, National Institutes for Food and Drug Control (\#2012X2). No writing assistance by persons other than the authors was used in the production of this manuscript.

\section{Disclosure}

The authors report no conflicts of interest in this work.

\section{References}

1. Lara HH, Garza-Trevino EN, Ixtepan-Turrent L, Singh DK. Silver nanoparticles are broad-spectrum bactericidal and virucidal compounds. J Nanobiotechnology. 2011;9:30.

2. Chen X, Schluesener HJ. Nanosilver: a nanoproduct in medical application. Toxicol Lett. 2008;176(1):1-12.

3. Tolaymat TM, El Badawy AM, Genaidy A, Scheckel KG, Luxton TP, Suidan M. An evidence-based environmental perspective of manufactured silver nanoparticle in syntheses and applications: a systematic review and critical appraisal of peer-reviewed scientific papers. $S c i$ Total Environ. 2010;408(5):999-1006.

4. Stensberg MC, Wei Q, McLamore ES, Porterfield DM, Wei A, Sepulveda MS. Toxicological studies on silver nanoparticles: challenges and opportunities in assessment, monitoring and imaging. Nanomedicine (Lond). 2011;6(5):879-898.

5. Bernacki J, Dobrowolska A, Nierwinska K, Malecki A. Physiology and pharmacological role of the blood-brain barrier. Pharmacol Rep. 2008;60(5):600-622.

6. Agarwal A, Lariya N, Saraogi G, Dubey N, Agrawal H, Agrawal GP Nanoparticles as novel carrier for brain delivery: a review. Curr Pharm. 2009;15(8):917-925.

7. Tang J, Xiong L, Wang S, et al. Distribution, translocation and accumulation of silver nanoparticles in rats. J Nanosci Nanotechnol. 2009;9(8):4924-4932.

8. Sharma HS, Ali SF, Hussain SM, Schlager JJ, Sharma A. Influence of engineered nanoparticles from metals on the blood-brain barrier permeability, cerebral blood flow, brain edema and neurotoxicity. An experimental study in the rat and mice using biochemical and morphological approaches. J Nanosci Nanotechnol. 2009;9(8):5055-5072.

9. Sharma HS, Ali SF, Tian ZR, et al. Chronic treatment with nanoparticles exacerbate hyperthermia induced blood-brain barrier breakdown, cognitive dysfunction and brain pathology in the rat. Neuroprotective effects of nanowired-antioxidant compound H-290/51. J Nanosci Nanotechnol. 2009;9(8):5073-5090.

10. Tang J, Xiong L, Zhou G, et al. Silver nanoparticles crossing through and distribution in the blood-brain barrier in vitro. J Nanosci Nanotechnol. 2010;10(10):6313-6317.

11. Trickler WJ, Lantz SM, Murdock RC, et al. Silver nanoparticle induced blood-brain barrier inflammation and increased permeability in primary rat brain microvessel endothelial cells. Toxicol Sci. 2010;118(1): $160-170$.

12. Mathiisen TM, Lehre KP, Danbolt NC, Ottersen OP. The perivascular astroglial sheath provides a complete covering of the brain microvessels: an electron microscopic 3D reconstruction. Glia. 2010;58(9): 1094-1103.

13. Hirrlinger J, Dringen R. The cytosolic redox state of astrocytes: maintenance, regulation and functional implications for metabolite trafficking. Brain Res Rev. 2010;63(1-2):177-188.

14. Scheiber IF, Dringen R. Astrocyte functions in the copper homeostasis of the brain. Neurochem Int. 2013;62(5):556-565.

15. Hohnholt MC, Geppert M, Luther EM, Petters C, Bulcke F, Dringen R. Handling of iron oxide and silver nanoparticles by astrocytes. Neurochem Res. 2013;38(2):227-239.

16. Luther EM, Schmidt MM, Diendorf J, Epple M, Dringen R. Upregulation of metallothioneins after exposure of cultured primary astrocytes to silver nanoparticles. Neurochem Res. 2012;37(8):1639-1648. 
17. Haase A, Rott S, Mantion A, et al. Effects of silver nanoparticles on primary mixed neural cell cultures: uptake, oxidative stress and acute calcium responses. Toxicol Sci. 2012;126(2):457-468.

18. Nakagawa S, Deli MA, Kawaguchi H, et al. A new blood-brain barrier model using primary rat brain endothelial cells, pericytes and astrocytes. Neurochem Int. 2009;54(3-4):253-263.

19. Gumbleton M, Audus KL. Progress and limitations in the use of in vitro cell cultures to serve as a permeability screen for the blood-brain barrier. J Pharm Sci. 2001;90(11):1681-1698.

20. Reichel A, Begley DJ, Abbott NJ. An overview of in vitro techniques for blood-brain barrier studies. Methods Mol Med. 2003;89: 307-324.

21. Gaillard PJ, de Boer AG. Relationship between permeability status of the blood-brain barrier and in vitro permeability coefficient of a drug. Eur J Pharm Sci. 2000;12(2):95-102.

22. Xu L, Li X, Takemura T, Hanagata N, Wu G, Chou LL. Genotoxicity and molecular response of silver nanoparticle (NP)-based hydrogel. J Nanobiotechnology. 2012;10:16.

23. Xu L, Shao A, Zhao Y, et al. Neurotoxicity of silver nanoparticles in rat brain after intragastric exposure. J Nanosci Nanotechnol. 2014; $14: 1-9$.

24. Hanada S, Fujioka K, Inoue Y, Kanaya F, Manome Y, Yamamoto K. Cell-based in vitro blood-brain barrier model can rapidly evaluate nanoparticles' Brain permeability in association with particle size and surface modification. Int J Mol Sci. 2014;15(2):1812-1825.

25. Panyala NR, Pena-Mendez EM, Havel J. Silver or silver nanoparticles: a hazardous threat to the environment and human health? J Appl Biomed. 2008;6:117-129.

26. Yang Z, Liu ZW, Allaker RP, et al. A review of nanoparticle functionality and toxicity on the central nervous system. JR Soc Interface. 2010;7(suppl 4):S411-S422.

27. Kim SH, Ko JW, Koh SK, et al. Silver nanoparticles induce apoptotic cell death in cultured cerebral cortical neurons. Mol Cell Toxicol. 2014;10(2):173-179.

28. Cramer S, Tacke S, Bornhorst J, Klingauf J, Schwerdtle T, Galla HJ. The influence of silver nanoparticles on the blood-brain and the bloodcerebrospinal fluid barrier in vitro. J Nanomed Nanotechnol. 2014; $5: 225$.

29. Sharma A, Muresanu DF, Patnaik R, Sharma HS. Size- and agedependent neurotoxicity of engineered metal nanoparticles in rats. $\mathrm{Mol}$ Neurobiol. 2013;48(2):386-396.

30. Lai $\mathrm{CH}$, Kuo KH. The critical component to establish in vitro BBB model: pericyte. Brain Res Brain Res Rev. 2005;50(2):258-265.

31. Allt G, Lawrenson JG. Pericytes: cell biology and pathology. Cells Tissues Organs. 2001;169(1):1-11.

32. Schiera G, Sala S, Gallo A, et al. Permeability properties of a three-cell type in vitro model of blood-brain barrier. J Cell Mol Med. 2005;9(2): 373-379.

33. Deli MA, Abraham CS, Kataoka Y, Niwa M. Permeability studies on in vitro blood-brain barrier models: physiology, pathology, and pharmacology. Cell Mol Neurobiol. 2005;25(1):59-127.

34. Sengillo JD, Winkler EA, Walker CT, Sullivan JS, Johnson M, Zlokovic BV. Deficiency in mural vascular cells coincides with bloodbrain barrier disruption in Alzheimer's disease. Brain Pathol. 2013; 23(3):303-310.

35. Bell RD, Winkler EA, Singh I, et al. Apolipoprotein E controls cerebrovascular integrity via cyclophilin A. Nature. 2012;485(7399):512-516.

36. Sagare AP, Bell RD, Zhao Z, et al. Pericyte loss influences Alzheimerlike neurodegeneration in mice. Nat Commun. 2013;4:2932.

37. Yin N, Liu Q, Liu J, et al. Silver nanoparticle exposure attenuates the viability of rat cerebellum granule cells through apoptosis coupled to oxidative stress. Small. 2013;9(9-10):1831-1841.
38. Rahman MF, Wang J, Patterson TA, et al. Expression of genes related to oxidative stress in the mouse brain after exposure to silver-25 nanoparticles. Toxicol Lett. 2009;187(1):15-21.

39. Junn E, Han SH, Im JY, et al. Vitamin D3 up-regulated protein 1 mediates oxidative stress via suppressing the thioredoxin function. J Immunol. 2000;164(12):6287-6295.

40. Perrone L, Devi TS, Hosoya K-I, Terasaki T, Singh LP. Thioredoxin interacting protein (TXNIP) induces inflammation through chromatin modification in retinal capillary endothelial cells under diabetic conditions. J Cell Physiol. 2009;221(1):262-272.

41. Chen C-L, Lin C-F, Chang W-T, Huang W-C, Teng C-F, Lin Y-S. Ceramide induces p38 MAPK and JNK activation through a mechanism involving a thioredoxin-interacting protein-mediated pathway. Blood. 2008;111(8):4365-4374.

42. Eom H-J, Choi J. p38 MAPK activation, DNA damage, cell cycle arrest and apoptosis as mechanisms of toxicity of silver nanoparticles in jurkat T cells. Environ Sci Technol. 2010;44(21):8337-8342.

43. Corradetti MN, Inoki K, Guan KL. The stress-inducted proteins RTP801 and RTP801L are negative regulators of the mammalian target of rapamycin pathway. J Biol Chem. 2005;280(11):9769-9772.

44. Lisse TS, Liu T, Irmler M, et al. Gene targeting by the vitamin D response element binding protein reveals a role for vitamin $\mathrm{D}$ in osteoblast mTOR signaling. FASEB J. 2011;25(3):937-947.

45. Li QX, Ke N, Sundaram R, Wong-Staal F. NR4A1, 2, 3 - an orphan nuclear hormone receptor family involved in cell apoptosis and carcinogenesis. Histol Histopathol. 2006;21(5):533-540.

46. Fu Y, Luo L, Luo N, Zhu X, Garvey WT. NR4A orphan nuclear receptors modulate insulin action and the glucose transport system: potential role in insulin resistance. J Biol Chem. 2007;282(43):31525-31533.

47. Volakakis N, Kadkhodaei B, Joodmardi E, et al. NR4A orphan nuclear receptors as mediators of CREB-dependent neuroprotection. Proc Natl Acad Sci U S A. 2010;107(27):12317-12322.

48. Sarkar S, Mukherjee S, Chattopadhyay A, Bhattacharya S. Low dose of arsenic trioxide triggers oxidative stress in zebrafish brain: expression of antioxidant genes. Ecotoxicol Environ Saf. 2014;107C:1-8.

49. Moore ED, Kooshki M, Metheny-Barlow LJ, Gallagher PE, Robbins ME. Angiotensin-(1-7) prevents radiation-induced inflammation in rat primary astrocytes through regulation of MAP kinase signaling. Free Radic Biol Med. 2013;65:1060-1068.

50. Chairuangkitti P, Lawanprasert S, Roytrakul S, et al. Silver nanoparticles induce toxicity in A549 cells via ROS-dependent and ROS-independent pathways. Toxicol In Vitro. 2013;27(1):330-338.

51. Bernoud N, Fenart L, Bénistant C, et al. Astrocytes are mainly responsible for the polyunsaturated fatty acid enrichment in blood-brain barrier endothelial cells in vitro. J Lipid Res. 1998;39(9):1816-1824.

52. Ozmen I, Naziroglu M, Alici HA, Sahin F, Cengiz M, Eren I. Spinal morphine administration reduces the fatty acid contents in spinal cord and brain by increasing oxidative stress. Neurochem Res. 2007;32(1): 19-25.

53. Liu Y, Guan W, Ren G, Yang Z. The possible mechanism of silver nanoparticle impact on hippocampal synaptic plasticity and spatial cognition in rats. Toxicol Lett. 2012;209(3):227-231.

54. Powers CM, Slotkin TA, Seidler FJ, Badireddy AR, Padilla S. Silver nanoparticles alter zebrafish development and larval behavior: distinct roles for particle size, coating and composition. Neurotoxicol Teratol. 2011;33(6):708-714.

55. Bak LK, Schousboe A, Waagepetersen HS. The glutamate/GABAglutamine cycle: aspects of transport, neurotransmitter homeostasis and ammonia transfer. J Neurochem. 2006;98(3):641-653.

56. Farina C, Aloisi F, Meinl E. Astrocytes are active players in cerebral innate immunity. Trends Immunol. 2007;28(3):138-145. 
International Journal of Nanomedicine

Dovepress

\section{Publish your work in this journal}

The International Journal of Nanomedicine is an international, peerreviewed journal focusing on the application of nanotechnology in diagnostics, therapeutics, and drug delivery systems throughou the biomedical field. This journal is indexed on PubMed Central, MedLine, CAS, SciSearch ${ }^{\circledR}$, Current Contents ${ }^{\circledR} /$ Clinical Medicine,
Journal Citation Reports/Science Edition, EMBase, Scopus and the Elsevier Bibliographic databases. The manuscript management system is completely online and includes a very quick and fair peer-review system, which is all easy to use. Visit http://www.dovepress.com/ testimonials.php to read real quotes from published authors.

Submit your manuscript here: http://www.dovepress.com/international-journal-of-nanomedicine-journal 